NASA Contractor Report 191096

$$
\begin{gathered}
11.33 \\
186036 \\
7 P
\end{gathered}
$$

\title{
Operation of High Power Converters in Parallel
}

D.K. Decker and L.Y. Inouye

TRW Space and Technology Group

Redondo Beach, California

March 1993

Prepared for

Lewis Research Center

Under Contract NAS3-25093 


\title{
OPERATION OF HIGH POWER CONVERTERS IN PARALLEL
}

\author{
D. K. Decker and L. Y. Inouye \\ TRW Space and Technology Group \\ Redondo Beach, Ca. 90278
}

\begin{abstract}
High power converters that are used in space power subsystems are limited in power handling capability due to component and thermal limitations. For applications, such as Space Station Freedom, where multi-kilowatts of power must be delivered to user loads, parallel operation of converters becomes an attractive option when . considering overall power subsystem topologies. TRW, under NASA contract NAS3-25093, has developed three different unequal power sharing approaches for parallel operation of converters. These approaches, known as droop, master-slave, and proportional adjustment, are discussed in this paper and test results are presented.
\end{abstract}

\section{INTRODUCTION}

TRW, under NASA contract NAS3-25093, has developed three different power sharing approaches for parallel operation of the Space Station Freedom 6.25 kW DC-DC converter units (DDCU). These approaches, known as droop, master-slave, and proportional adjustment, have been incorporated in the TRW breadboard DDCUs used in the space station power management and distribution (PMAD) dc test bed at Lewis Research Center, where system operation has been verified.

\section{$6.25 \mathrm{~kW} \mathrm{DC-DC}$ Converter Unit Description}

The $6.25 \mathrm{~kW}$ DDCU provides isolation between the space station main bus and the 120 vdc secondary bus. The DDCU block diagram, as shown in Figure 1, consists of an input filter, a $20 \mathrm{kHz}$ series resonant dc-ac inverter, output rectifiers, and an output filter. The control electronics provide output regulation and output current limit functions. A dc-dc converter operating from the main input voltage provides control power for the DDCU. A Mil-Std-1553 data bus controller interfaces command and telemetry functions between the DDCU and the space station controllers. The series resonant inverter concept of the DDCU is based on the parallel resonant inverter that was used in the main inverter unit (MIU) for the space station 20 $\mathrm{kHz}$ power subsystem. The series resonant inverter power stage schematic is shown in Figure 2. It includes two insulated gate bipolar transistor (IGBT) power switches, Q1 and Q2, that operate at $50 \%$ duty cycle and two IGBT power switches, Q3 and Q4, that operate in a pulse width modulated fashion to control output voltage or output current. A unique feature of this concept is that no energy is ever returned to the source.

The converter operates from a 125-170 vdc bus and provides a regulated output voltage which is programmable from 120 to 138 vdc. Efficiency curves from two $6.25 \mathrm{~kW}$ units operating in parallel are shown in Figure 3.

\section{Current Mode Master/Slave Control}

In the current program method of control, forced current sharing of multiple power stages is not necessary, since a common error signal controls the peak currents in each power stage, resulting in automatic current sharing. A block diagram implementation of the current mode master/slave control is shown in Figure 4. An error amplifier compares the output voltage against a reference and generates an error voltage Eo, that is used as a reference for the comparators to control the switch currents in each power stage. A ramp is added for stability. The output of the comparator is the PWM signal that controls the turn-on and turn-off of the power transistors in each power stage. In this control scheme, the two power channels share current equally. Switch currents for each channel are shown in Figure 5. Output current sharing data is presented in Figure 6. 


\section{Current Mode Proporational Adjustment Control}

The current mode proporational adjustment control method is similar to the master/slave control with one exception. A multiplier is added in series with the output error signal to modify the reference for the PWM comparators (See Figure 7). By commanding different ratio references into the multipliers, unequal power sharing can be obtained from the converters. With both of the ratio commands set to 100 percent, the current sharing shown in Figure 6 is obtained. By offsetting the ratios, one at 100 percent and the other at 90 percent, the current sharing shown in Figure 8 is obtained. By changing the ratios, other current sharing values can be obtained.

\section{Droop Mode Control}

The third power sharing approach is the droop mode control.' This approach, unlike the other two, does not require any control signals to be shared between the two parallel converters. Power sharing, whether equal or unequal is accomplished by drooping the output voltage regulation point as a function of its load current. a block diagram implementation is presented in Figure 9. An error signal which is proporational to output current is introduced into the output voltage divided as shown in Figure 9. As output current increases, the voltage regulation point droops, resulting in a negative feedback effect when two converters are connected in parallel. By adjusting the current to voltage ratio of the divider current feedback network for each converter, equal or unequal output current sharing can be achieved. Figure 10 shows data for equal current sharing of the converters operating in the droop mode controt: Figure 11 shows data for unequal current sharing for various current to voltage ratio.

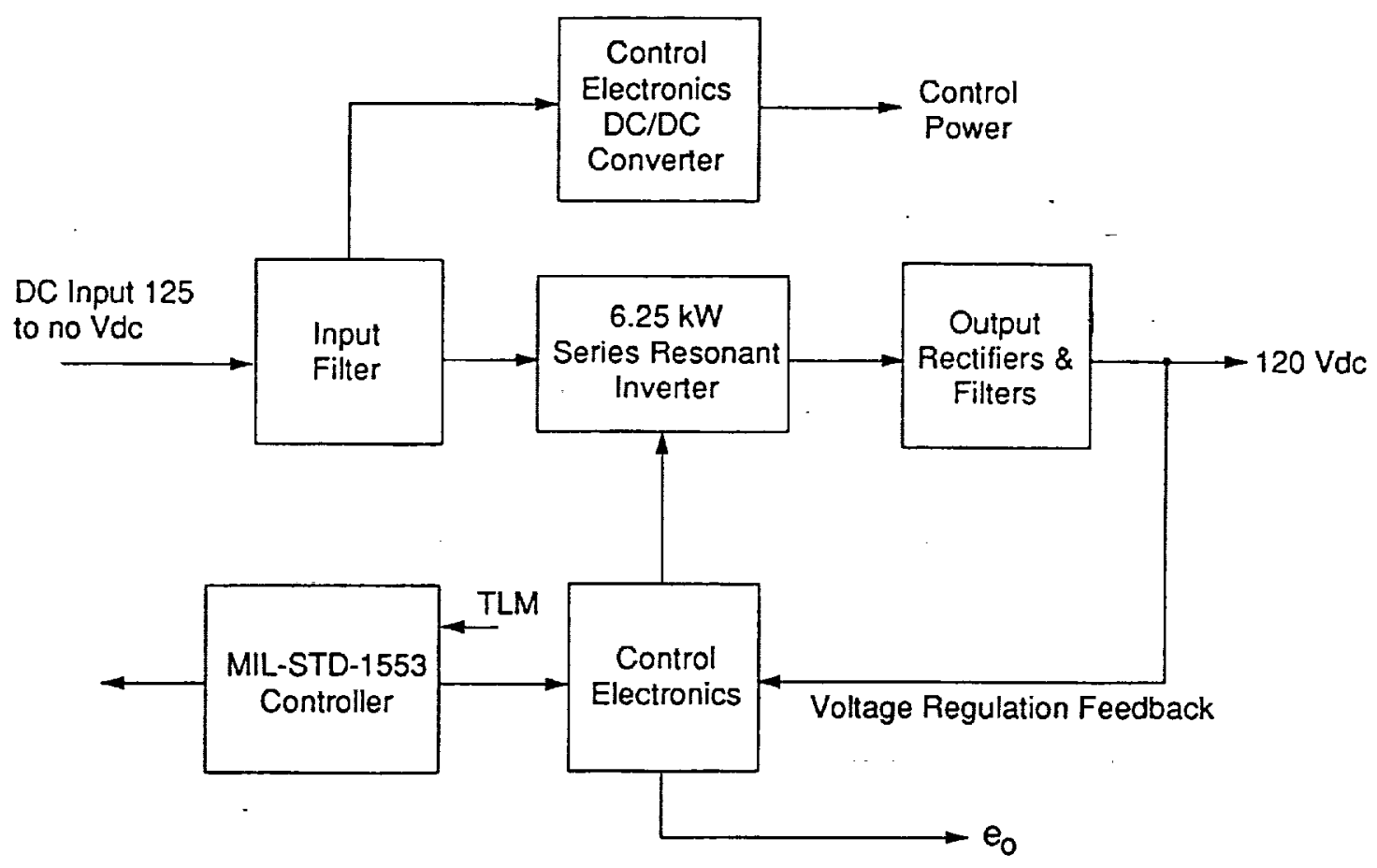

Figure 1. DC-DC Converter Block Diagram 

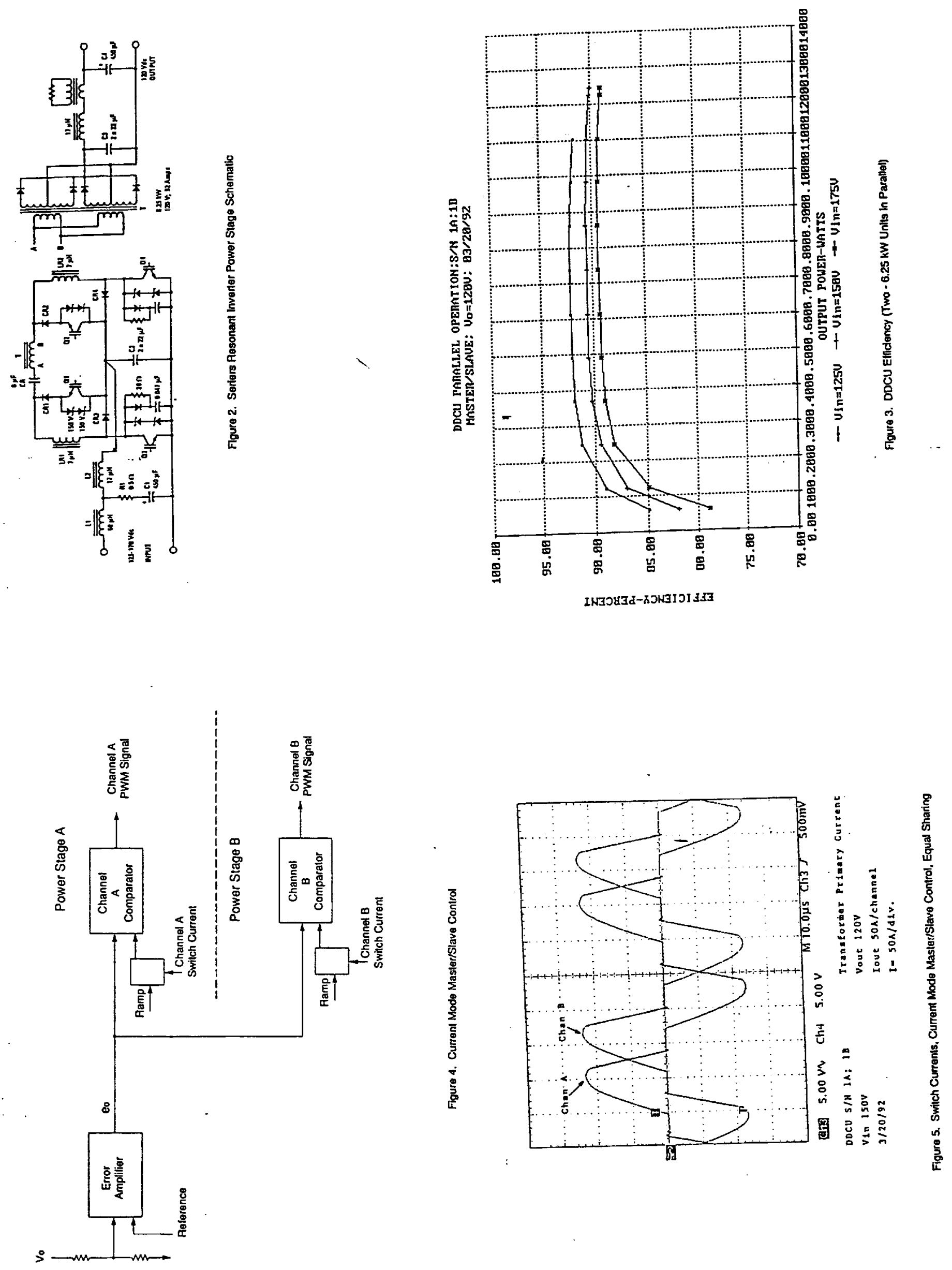

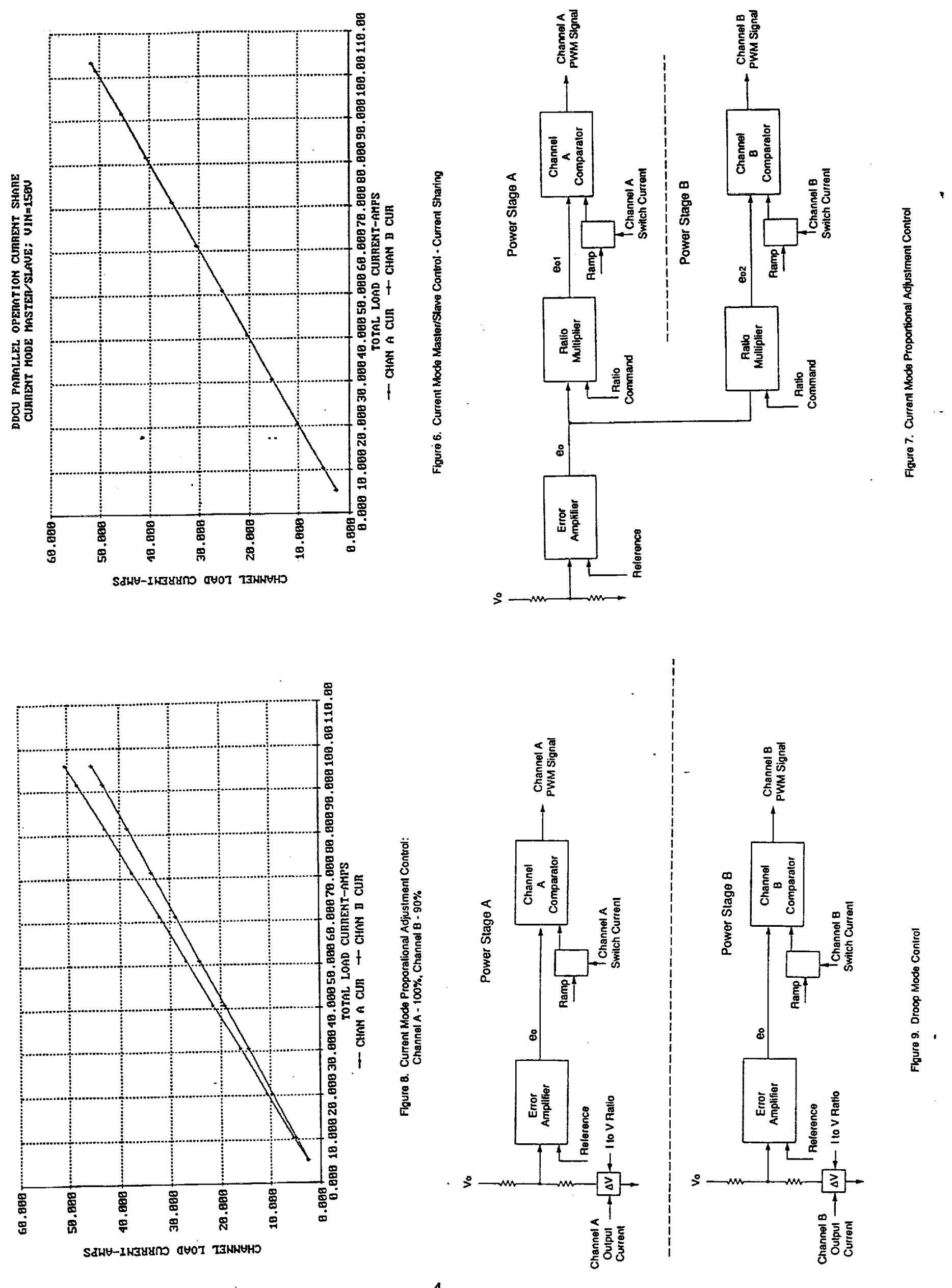


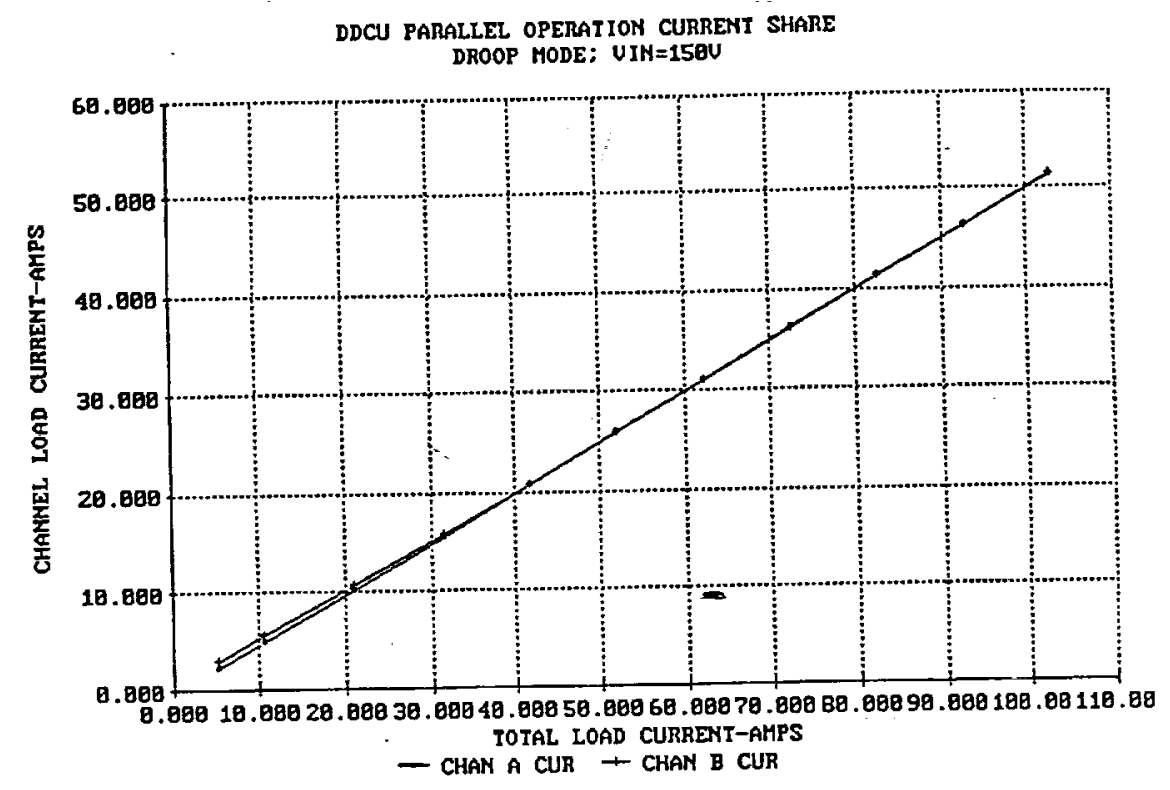

Figure 10. Droop Mode Control, Equal Current Sharing

DDCU PARALLEL OPERATIOH SJH

DROOP HODE: 63/20/92; U in $=1584$

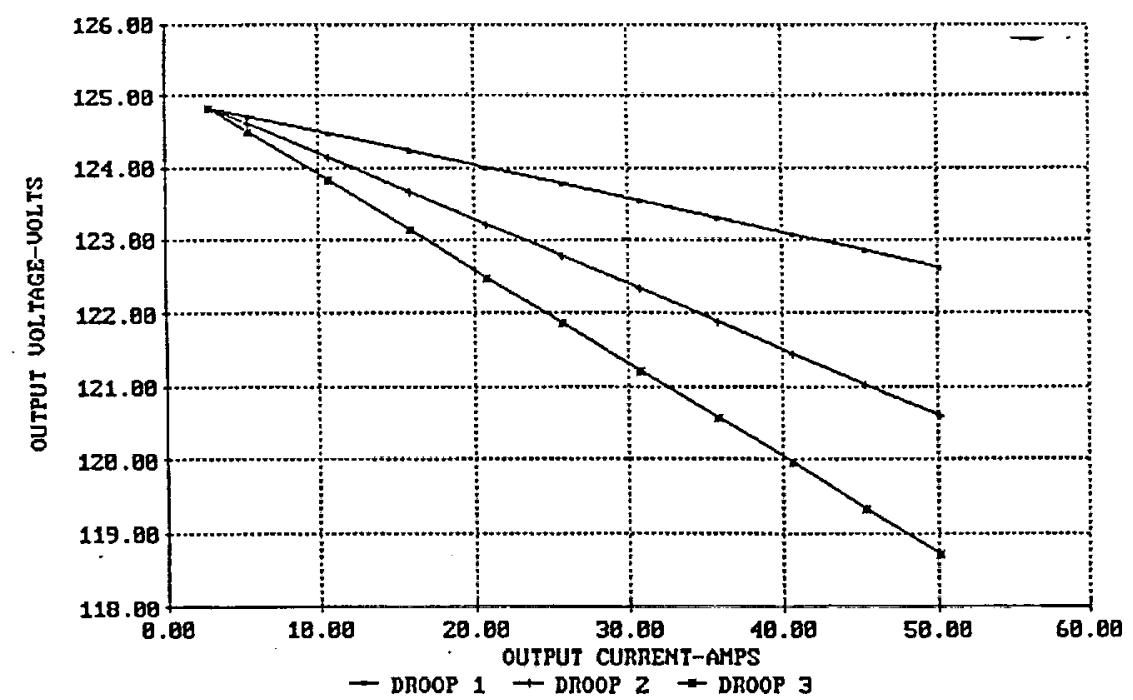

Figure 11. Droop Mode Control, Unequal Current Sharing 
Publc reporting burden for this collection of information is estimated to average 1 hour per response, including the time for reviewing instructions, searching existing data sources,

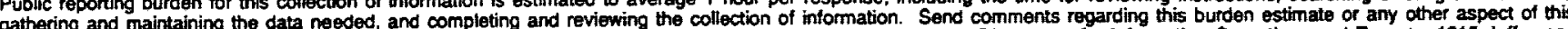
gathertion of information including suggestions for reducing this burden, to Washington Headquarters Services, Directorate for Intormation Operations and Reports, 1215 Jefferson Davis Highway, Suite 1204, Artington, VA 22202-4302, and to the Office of Management and Buoget, Papenwork Reduction Project (0704-0188), Washington, DC 20503.

\begin{tabular}{|l|l|l|l|}
\hline 1. AGENCY USE ONLY (Leave blank) & $\begin{array}{c}\text { 2. REPORT DATE } \\
\text { March } 1993\end{array}$ & $\begin{array}{r}\text { 3. REPOAT TYPE AND DATES COVERED } \\
\text { Final Contractor Report }\end{array}$ \\
\hline 4
\end{tabular}

4. TITLE AND SUBTTILE

Operation of High Power Converters in Parallel

6. AUTHOR(S)

D.K. Decker and L.Y. Inouye

\section{PERFORMING ORgANZATION NAME(S) AND ADDRESS(ES)}

TRW Space and Technology Group

Redondo Beach, California 90278
$\mathrm{WU}-474-42-10$

C-NAS3-25093

8. PERFORMING ORGANIZATION REPORT NUMBER

E-7685

10. SPONSORING/MONITORING AGENCY REPORT NUMBER

NASA CR-191096

National Aeronautics and Space Administration

Lewis Research Center

Cleveland, Ohio 44135-3191

\section{SUPPLEMENTARY NOTES}

Project Manager, Raymond F. Beach, Electrical Systems Division, (216) 433-5320.

12a. DISTAIBUTION/AVAILABILITY STATEMENT

12b. DisTRIBUTION CODE

Unclassified - Unlimited

Subject Category 33

\section{ABSTRACT (Maximum 200 words)}

High power converters that are used in space power subsystems are limited in power handling capability due to component and thermal limitations. For applications, such as Space Station Freedom, where multi-kilowatts of power must be delivered to user loads, parallel operation of converters becomes an attractive option when considering overall power subsystem topologies. TRW, under NASA contract NAS3-25093, has developed three different unequal power sharing approaches for parallel operation of converters. These approaches, known as droop, master-slave, and proportional adjustment, are discussed in this paper and test results are presented.

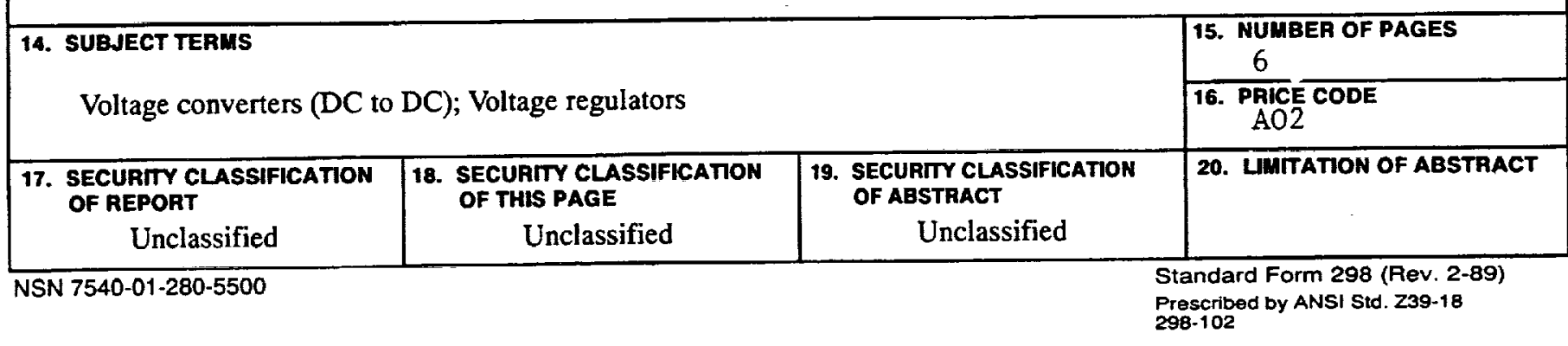

